\title{
Reliability studies on reinforced concrete beam subjected to bending forces with natural stone as coarse aggregate
}

\author{
Daniel Ndakuta Kolo ${ }^{1}$ (D) James Isiwu Aguwa ${ }^{1}$. Theophilus Yisa Tsado ${ }^{1}$ Mohammed Abdullahi ${ }^{1}$. \\ Abdulazeez Yusuf ${ }^{1}$. Sikiru Folahan Oritola ${ }^{1}$
}

Received: 30 June 2020 / Accepted: 5 November 2020 / Published online: 22 November 2020

(c) The Author(s) 2020

\begin{abstract}
This paper presents the results of structural reliability analysis of a structural element (beam) in building using First-order reliability method (FORM) to ascertain the level of safety. The natural stone (NS) which is the by-product of Precambrian deposits of the Bida trough was used as coarse aggregate: unwashed and washed aggregates were used. A total of 80 concrete cubes of $150 \mathrm{~mm} \times 150 \mathrm{~mm} \times 150 \mathrm{~mm}$ were cast and used for this study, sensitivity analysis was conducted by varying the span, depth, effective depth, area of shear reinforcement and dead load of the beam in bending. The result of the sensitivity analysis revealed that the beam utilising unwashed and washed NS are both structurally safe at a span of $3000 \mathrm{~mm}$ with probabilities of failure of $9.20 \times 10^{-5}$ and $2.06 \times 10^{-8}$ and both safe at a depth of $600 \mathrm{~mm}$ with probabilities of failure of $4.19 \times 10^{-4}$ and $2.602 \times 10^{-4}$, respectively, in bending.
\end{abstract}

Keywords Beam $\cdot$ Bending $\cdot$ Natural stones $\cdot$ Concrete $\cdot$ Structural reliability

\section{Introduction}

Concrete is the most widely used construction material in the world, second to water as the most utilised substance on earth (Alhaji 2016). It is obtained by mixing cement, water and aggregates in right quantities (with admixtures). Aggregates ideally constitute $75 \%$ of concrete as they are extremely important in the quality of concrete produced, this makes it important that they meet certain standards in order to achieve a strong, durable and economical concrete.

Concrete compressive, tensile and flexural strengths are measures used in determining the amount of resistance a structural element can offer to deformation, they remain the most important properties of concrete. Several researches have been conducted and many are still being conducted on the relationship between the composition of structural concrete and its mechanical properties. Despite the seemingly huge interest in the study of concrete, cases of poor construction and structural failure still exist (Alhaji 2016).

Daniel Ndakuta Kolo

daniel.kolo@futminna.edu.ng

1 Department of Civil Engineering, Federal University of Technology, Minna, Nigeria
In any structure, there exist uncertainties or variability in loading and material properties. These uncertainties lead to variability in structural response during the life cycle of a structure (Jalayer et al. 2011). In order to design structures that can perform the intended purpose with desired confidence, these uncertainties involved must be taken into account. The traditional way to tackle these uncertainties is to use the extreme values of the uncertain quantities and/or safety factors in the framework of deterministic design. However, a more accurate and precise way of treating the uncertainties is by utilising probability-based design methods that have been evolving and gaining widespread acceptability for the past few decades (Ayyub et al. 1995; Wen 2000).

In order to ensure durability, functionality (serviceability and limit states) and safety (ultimate limit state), the evaluation of the structural behaviour of the reinforced concrete (RC) systems in different loading conditions is a primary requirement. Advanced tools like non-linear finite element analyses $\left(\mathrm{NLFEA}_{\mathrm{s}}\right)$ is one of the solutions being utilised for the design of complex new RC structures. Reliability assessment of reinforced concrete structures always involves two different types of uncertainties namely: aleatory and epistemic uncertainties (Castaldo et al. 2020). The aleatory uncertainties affect material properties and geometry, while the epistemic uncertainties are related to assumptions performed within the NLFEA . $_{\text {. }}$ 
The natural stone (NS) utilised is mostly found in Bida basin (Trough), it is a by-product of the Precambrian decomposition, transportation and deposition of rocks in this Basin. It is an extension of the Iullemmeden Basin which runs through Niger Republic and Mali in West Africa. Bida basin is found in Northern Nigeria and is delimited to the North East and South West by Basement Complex. The Precambrian rocks in Northern Nigeria can generally be classified into four groups namely: Basement Complex, Older Granite series, Younger Metasediments and Volcanic Rocks. This research investigates the effects of utilising washed and unwashed NS in structural elements.

The use of natural stone (NS) sourced from Bida for concrete production is gaining wide acceptance especially among the dwellers of the Bida basin because the production of crushed granite is more labour intensive and expensive. However, despite the wide acceptance of its use, the body of literature is still not robust with research related to the use of the NS as coarse aggregate for concrete production. The NS is used conveniently for mass concrete production and not commonly used for suspended reinforced concrete elements such as beams, columns or slabs because the structural reliability in that regard has not been evaluated. Jalayer et al. (2011) used a constant water-cement ratio of 0.65 to produce concrete with the NS as coarse aggregates, this research determined just the compressive strength of the concrete at 3, 7, 14, 21 and 28 days of curing. The flexural strength, splitting tensile strength and elastic modulus were not considered. Furthermore, Alhaji (2016) developed statistical models for predicting the compressive strength, flexural strength, splitting tensile strength and elastic modulus of concrete produced from the NS. Currently, no research exists on structural reliability studies of concrete produced utilising this coarse aggregate. Based on this premise, reliability studies on the NS concrete become timely and justifiable.

Reliability in structural engineering is a means through which the performance or functionality of a structural system is assessed. It is a measure of the safety of the structural components and subsequently that of the whole system. Reliability analysis is a tool to predict to a certain acceptable degree, the ability of the system or components to fulfil the design function under given conditions within the structural design life (Abubakar 2015).

The objective of any structural design is to ensure safety and economy of the structure operating under a given environment. For this purpose, designers always check whether the capacity of the structure exceeds the demand as shown in Eq. (1):

$$
\text { Capacity }(C)>\operatorname{Demand}(D)
$$

As far as the condition in (1) is satisfied, the safety of the structure is ensured for the intended purpose for which the structure is built. As long as the strength exceeds the stress on a component, safety is anticipated (Barambu et al. 2017). RC structures usually undergo degradation, this could manifest in the form of changes to strength and stiffness beyond the baseline conditions assumed during structural design (Castaldo et al. 2017). These ageing effects could result in degradation of structural components most especially when $\mathrm{RC}$ is exposed to aggressive environment, increasing the probability of structural failure (Castaldo et al. 2017). The reliability assessment performed on the NS in this study, however, does not incorporate the time-dependent and environmental effects on the concrete.

The aim of this study is to conduct structural reliability studies on reinforced concrete beam subjected to bending forces with natural stone as coarse aggregate. The objectives are to (i) determine the physical properties of fine and coarse aggregates; (ii) determine the 28-day compressive strength of concrete cubes produced using unwashed and washed natural stone and (iii) determine the reliability indices for the structural element.

\section{Materials and methods}

\section{Ordinary portland cement (OPC)}

The Cement used was obtained from the Building Materials Market Minna, Niger State. The bags of Cement were stored on a raised platform where adequate protection from external effect was guaranteed. The OPC conforms with BS 12 (1996).

\section{Fine aggregate}

The sand was collected from Chanchaga, Minna, Niger State. It was ensured that the sand was clean, sharp, free from clay and dirt. Fine aggregates generally refer to aggregates passing through sieve size $4.75 \mathrm{~mm}$ BS 882 (1992).

\section{Water}

Water fit for drinking was sourced from the Civil Engineering Laboratory, Federal University of Technology Minna and used in casting the cubes. BS EN 1008 (2002) stipulates that water to be used for concrete production must be clean, drinkable and free from deleterious materials. 


\section{Coarse aggregate}

The Coarse aggregate used for this work was sourced from Bida, Niger State, Nigeria. Bida is located in the Middle belt region of Nigeria within Latitude $\mathrm{N} 9^{\circ} 55^{\prime} \mathrm{E}$ and Longitude $\mathrm{N} 5^{\circ} 52^{\prime} \mathrm{E}$. The coarse aggregate conforms to specifications for natural aggregates as in BS 882 (1992).

\section{Casting of concrete cubes for compressive strength test}

The mix design method employed in this study is the British Standard mix design (DoE) method. The Concrete specimens tested were cast in $150 \mathrm{~mm} \times 150 \mathrm{~mm} \times 150 \mathrm{~mm}$ moulds for compressive strength test. The samples were thoroughly mixed with the aid of a concrete mixer until the desired homogeneity of the mixture was achieved. The standard iron moulds of $150 \mathrm{~mm} \times 150 \mathrm{~mm} \times 150 \mathrm{~mm}$ were used, it was ensured that the moulds were well lubricated with oil in order to reduce friction and enhance the removal of cubes from the mould. Each mould was then filled with concrete in three layers each tampered 25 times. 80 cubes were cast in total, 40 cubes for the unwashed NS and 40 for the washed NS. The cubes were cured for 28 days using ponding method of curing. Cube casting was performed in accordance to BS 1881 (1983).

\section{Compressive strength test}

Compressive strength test on concrete cubes (80 Cubes) was determined using the compressive testing machine. The weight of each cube was taken before crushing, this is, however, a destructive method of testing cubes. After crushing, the compressive strengths were calculated using Eq. (2). The test was conducted in accordance with BS 1881:116.

$F_{\text {cu }}=\frac{\text { Average load }}{\text { Area }}\left(\mathrm{N} / \mathrm{mm}^{2}\right)$

\section{Reliability assessment}

First-Order Reliability Method (FORM) was utilised in assessing the reliability of the structural element under consideration. This method is a simplified reliability model, it uses only the mean values and standard deviations for load and resistance values in a particular limit state in order to obtain the reliability index. The knowledge of type of distribution for the random variables is not needed for this analysis, hence all variables were assumed to be normally distributed.

\section{Bending failure}

Table 1 presents a summary of the input parameters utilised for the reliability analysis of the reinforced concrete beam subjected to bending forces. The input parameters are normally distributed because first-order reliability method (FORM) was used for analysis. All dimensional properties are treated as normal distribution.

Figures 1 and 2 present Probability Density Plots (PDF) for the compressive strength of concrete produced using unwashed and washed natural stones, respectively. The PDF plots are in complete agreement with normal distribution used in the reliability analysis.
Table 1 Input data for bending failure

\begin{tabular}{llllll}
\hline Input parameter & $\mathrm{X}_{\mathrm{i}}$ & Mean & C.O.V & $\begin{array}{l}\text { Std. } \\
\text { Dev }\end{array}$ & Distribution \\
\hline Slab thickness, hs $(\mathrm{mm})$ & & & & & \\
Beam height, $\mathrm{h}(\mathrm{mm})$ & $\mathrm{X}_{1}$ & 150 & 0.07 & 10.50 & Normal \\
Beam width, b $(\mathrm{mm})$ & $\mathrm{X}_{2}$ & 400 & 0.05 & 20.00 & Normal \\
Effective depth of beam, $\mathrm{d}(\mathrm{mm})$ & $\mathrm{X}_{3}$ & 225 & 0.05 & 11.25 & Normal \\
Unit weight of concrete, & $\mathrm{X}_{4}$ & 359 & 0.05 & 17.95 & Normal \\
Diameter of tension bar, $\phi(\mathrm{mm})$ & $\mathrm{X}_{5}$ & 24 & 0.04 & 0.96 & Normal \\
Area of tension reinforcement, As $\left(\mathrm{mm}^{2}\right)$ & $\mathrm{X}_{6}$ & 16 & 0.04 & 0.64 & Normal \\
Area of shear reinforcement, Asv $\left(\mathrm{mm}^{2}\right)$ & $\mathrm{X}_{7}$ & 402 & 0.04 & 16.08 & Normal \\
Yield strength of steel, $f_{\mathrm{y}}\left(\mathrm{N} / \mathrm{mm}{ }^{2}\right)$ & $\mathrm{X}_{8}$ & 101 & 0.04 & 4.04 & Normal \\
Compressive strength of concrete, $\mathrm{f}_{\mathrm{cu}}\left(\mathrm{N} / \mathrm{mm}^{2}\right)$ & $\mathrm{X}_{9}$ & 460 & 0.05 & 23.00 & Normal \\
Dead load intensity, DL $(\mathrm{kN} / \mathrm{m})$ & $\mathrm{X}_{10}$ & 22.52 & 0.25 & 5.63 & Normal \\
Live load intensity, $\mathrm{LL}(\mathrm{kN} / \mathrm{m})$ & $\mathrm{X}_{11}$ & 17.70 & 0.10 & 1.77 & Normal \\
Span of beam, $\mathrm{L}(\mathrm{mm})$ & $\mathrm{X}_{12}$ & 3.33 & 0.18 & 0.60 & Normal \\
\hline
\end{tabular}

C.O.V coefficient of variation, $S t d$. dev standard deviation 


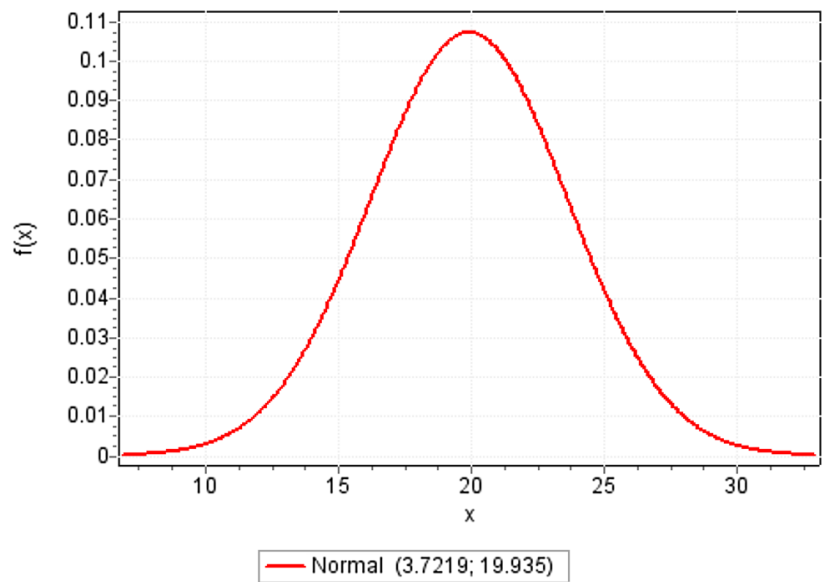

Fig. 1 Probability density function for compressive strengths of unwashed natural stone (NS)

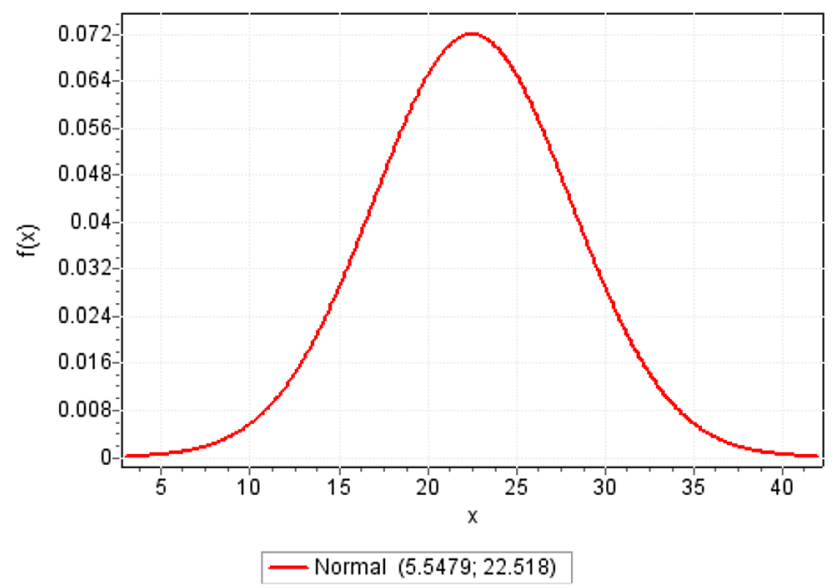

Fig. 2 Probability density function for compressive strengths of washed natural stone (NS)

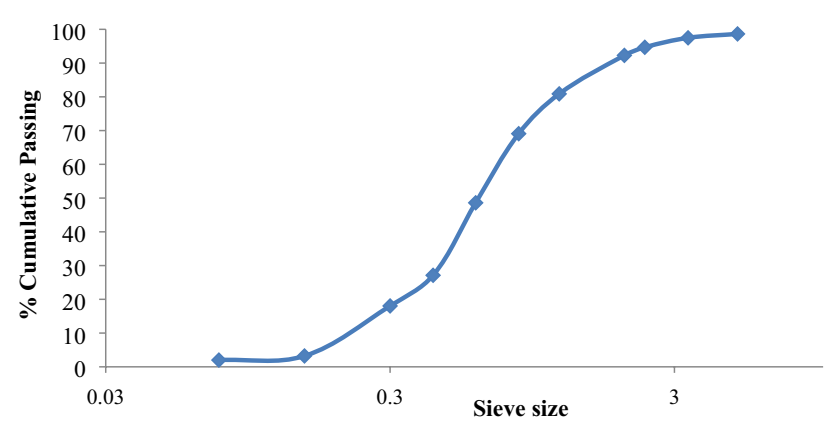

Fig. 3 Sieve analysis result for fine aggregate
The maximum bending moment at the mid-span of a simply supported beam is represented by Eq. (3):

$M_{u}=\frac{1}{8} \mathrm{wl}^{2}$

In order to satisfy flexural strength requirements, the maximum bending moment must conform to the inequality $M_{\mathrm{u}} \leq M_{\mathrm{R}}$, where $M_{\mathrm{u}}=$ Maximum bending Moment. $M_{\mathrm{R}}=$ Ultimate Moment of resistance.

\section{Performance Function}

Equation (4) presents the equation for beam performance function

$Z=R-S$

( $R$ Resistance, $S$ Load effect)

$K=\frac{M}{\mathrm{f}_{\mathrm{cu}} b d^{2}}$

$\mathrm{M}=\mathrm{Kf}_{\mathrm{cu}} \mathrm{bd}^{2}$

$g_{1}(X)=0.156 \mathrm{f}_{\mathrm{cu}} \mathrm{bd}^{2}-\frac{w L^{2}}{8}$

For a balanced reinforced concrete beam section, the performance function is enumerated as shown in Eq. (6):

$\mathrm{g}_{1}(\mathrm{X})=\mathrm{g}_{1}(X)=0.87 f_{\mathrm{y}} \mathrm{A}_{\mathrm{s}}\left(\mathrm{d}-\frac{0.87 \mathrm{f}_{y} A_{s}}{0.9 \mathrm{f}_{\mathrm{cu}} b}\right)-\mathrm{wl}^{2}$
$g_{1}(X)=0.87 f_{y} A_{s}\left(d-\frac{0.87 f_{y} A_{s}}{0.9 f_{c u} b}\right)-\frac{(1.4 D L+1.6 L L) L^{2}}{8}$,

where $f_{y}$ yield strength of steel, $A_{s}$ area of tension reinforcement, $d$ effective depth of beam, $\mathrm{F}_{\mathrm{cu}}$ Compressive strength of concrete, DL Dead load, LL live load. 


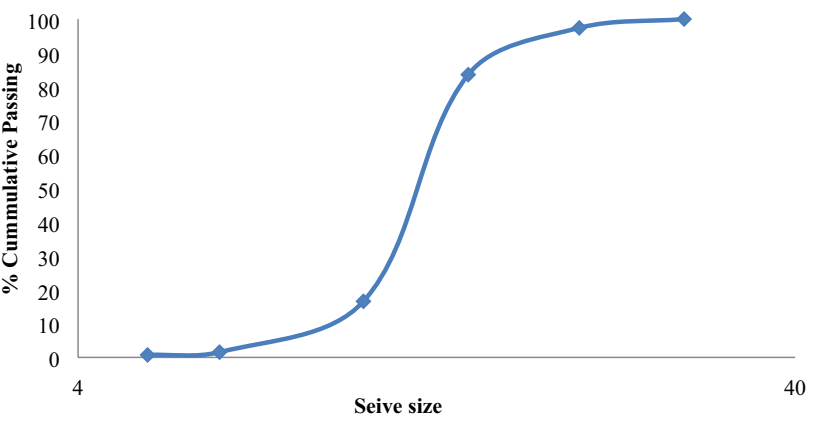

Fig. 4 Sieve analysis result for coarse aggregate (NS)

Table 2 Specific gravity result for Fine Aggregate

\begin{tabular}{llll}
\hline Trials & 1 & 2 & 3 \\
\hline Weight of cylinder & 115.0 & 116.5 & 16.6 \\
Weight of cylinder + sample & 207.2 & 240.6 & 248.9 \\
Weight of cylinder + sample + water & 87.3 & 512.0 & 484.9 \\
Weight cylinder + water & 428.0 & 435.7 & 402.2 \\
Specific gravity of sample (S.G) & 2.80 & 2.60 & 2.70 \\
Average specific gravity (S.G) & & 2.70 & \\
\hline
\end{tabular}

Table 3 Specific gravity result for Coarse Aggregate (NS)

\begin{tabular}{lllr}
\hline Trials & 1 & 2 & 3 \\
\hline Weight of cylinder & 115.0 & 116.5 & 116.6 \\
Weight of cylinder + sample & 307.2 & 328.4 & 325.9 \\
Weight of cylinder + sample + water & 553.2 & 566.5 & 533.3 \\
Weight cylinder + water & 438.7 & 34.6 & 402.6 \\
Specific gravity of sample (S.G) & 2.50 & 2.65 & 2.66 \\
Average specific gravity (S.G) & & 2.60 &
\end{tabular}

\section{Performance function linearisation}

From Eq. (6), substituting $f_{y}=\mathrm{X}_{9} f_{c u}=\mathrm{X}_{10}, \mathrm{DL}=\mathrm{X}_{11}$, $\mathrm{LL}=\mathrm{X}_{12}$ and linearising yields Eq. (7) which is a linearised version of the beam performance function

$$
\begin{aligned}
g_{1}(X)= & 125556.66 \mathrm{X}_{9}-604.03984 \mathrm{X}_{9}^{2} \mathrm{X}_{10}^{-1} \\
& -1575000 \mathrm{X}_{11}-1800000 \mathrm{X}_{12}
\end{aligned}
$$

\section{Results and discussion}

Figures 3 and 4 present the sieve analysis result obtained for fine and coarse aggregates, respectively, a Coefficient of uniformity $\left(C_{\mathrm{u}}\right)$ of 3.5 was obtained for the fine aggregate, while for the coarse aggregate $C_{u}$ value of 1.22 was

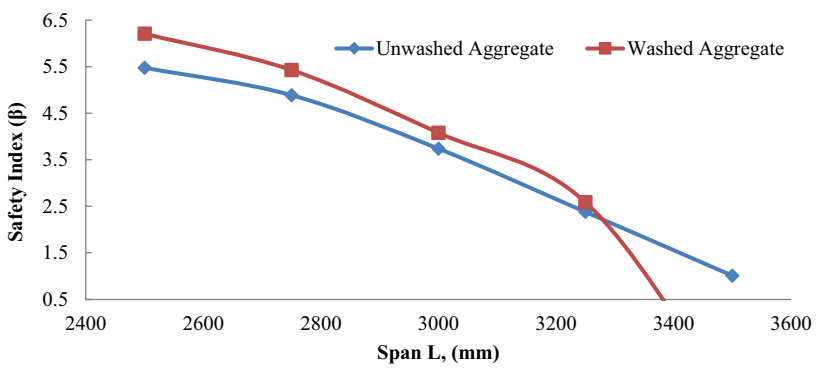

Fig. 5 Relationship between safety index and span of beam in bending for washed and unwashed $\mathrm{N}$

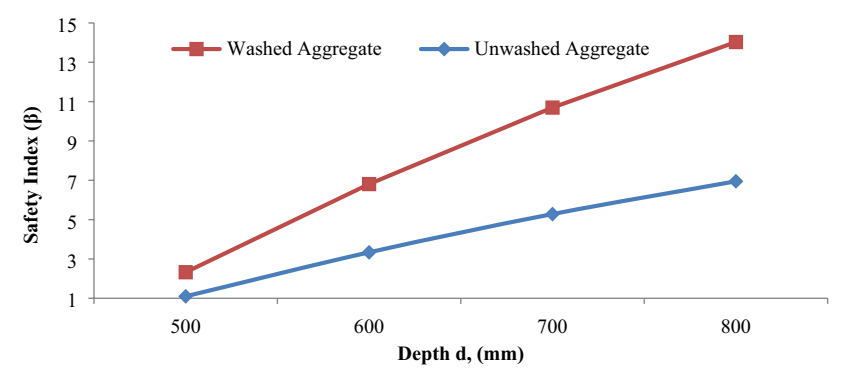

Fig. 6 Relationship between safety index and depth of beam in bending for washed and unwashed NS aggregate

obtained. In order to classify a soil as well graded, the $C_{\mathrm{u}}>6$ (Arora 2003), hence it is concluded that both aggregates are not well graded.

\section{Aggregate specific gravity test}

Table 2 presents the results for specific gravity test performed on fine aggregate, an average specific gravity of 2.7 was obtained and is within the natural aggregates range of 2.6-2.7 (Neville and Brooks 2008).

Table 3 presents the results for specific gravity test performed on the coarse aggregate, an average specific gravity of 2.6 was obtained and is within the natural aggregates range of 2.6-2.7 (Neville and Brooks 2008). This implies that the aggregate is suitable for construction work. 


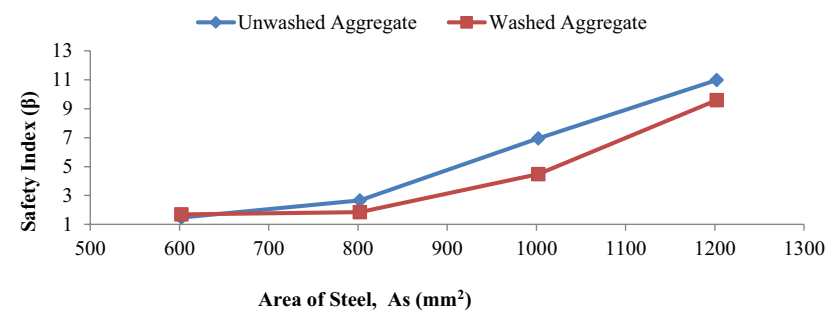

Fig. 7 Relationship between safety index and area of tension reinforcement in Bending for washed and unwashed NS aggregate

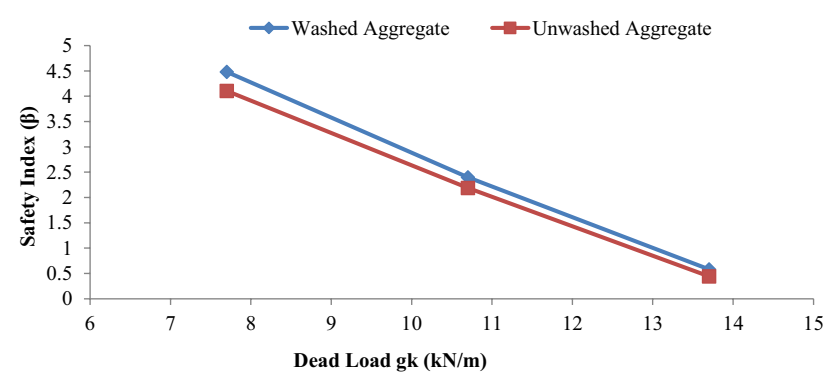

Fig. 8 Relationship between safety index and dead load of beam in bending for washed and unwashed aggregate

\section{Sensitivity analysis}

Figure 5 presents the result of sensitivity analysis conducted in bending for both unwashed and washed NS varying the beam span (L). As seen from Fig. 5, increasing the beam span reduces the safety level with reliability indices lower than the 3.0 target reliability $\left(\beta_{\mathrm{T}}\right)$, whereas decrease in the span increases the safety level for the concrete under consideration. The beam is reliable at span of $3000 \mathrm{~mm}$ with reliability index of 3.74 and 4.08 for unwashed and washed aggregates, respectively. Increasing the span of beams increases the bending moment experienced which contributes to the bending of beams. The washed aggregates gave higher reliability indices when compared with the unwashed aggregates. This result is in line with the findings of research by Ogunbiyi et al. (2017) and Ode and Eluozo (2016) where washed aggregates performed better than unwashed aggregates in concrete production.

Figure 6 presents the result of sensitivity analysis conducted in bending for both unwashed and washed NS varying the beam depth (d). A general increase in safety index $(\beta)$ was observed as the depth was increased from 400 to $800 \mathrm{~mm}$. As seen the washed aggregates recorded higher reliability indices when compared with unwashed aggregates.

Figure 7 presents the sensitivity analysis conducted in bending for both unwashed and washed NS varying the Area of Tension reinforcement $\left(A_{\mathrm{s}}\right)$. A general increase in safety index $(\beta)$ was obtained as the Area of steel reinforcement was increased. As seen on Fig. 7, the unwashed aggregates recorded higher reliability indices values when compared with the washed aggregates for bending, varying the $A_{\mathrm{s}}$.

Figure 8 presents the result of sensitivity analysis conducted in bending for unwashed and washed NS varying the beam dead load $\left(g_{\mathrm{k}}\right)$. A general increase in safety index $(\beta)$ was obtained as the design dead load was reduced (unwashed and washed aggregate).

\section{Conclusion}

The following conclusion is drawn from the study: the reinforced concrete beam utilising the natural stone (NS) as coarse aggregate is structurally safe at a span of $3000 \mathrm{~mm}$ utilising unwashed and washed NS with Probabilities of failure of $9.20 \times 10^{-5}$ and $2.06 \times 10^{-8}$, respectively, and depth of $600 \mathrm{~mm}$ for both unwashed and washed NS with probabilities of failure of $4.19 \times 10^{-4}$ and $2.602 \times 10^{-4}$, respectively, in bending. The safety index is very sensitive to the span and depth of the beam, hence they are the critical factors to be put into consideration when designing reinforced concrete beam utilising the NS as coarse aggregate.

\section{Compliance with ethical standards}

Conflict of interest On behalf of all authors, the corresponding author states that there is no conflict of interest.

Open Access This article is licensed under a Creative Commons Attribution 4.0 International License, which permits use, sharing, adaptation, distribution and reproduction in any medium or format, as long as you give appropriate credit to the original author(s) and the source, provide a link to the Creative Commons licence, and indicate if changes were made. The images or other third party material in this article are included in the article's Creative Commons licence, unless indicated otherwise in a credit line to the material. If material is not included in the article's Creative Commons licence and your intended use is not permitted by statutory regulation or exceeds the permitted use, you will need to obtain permission directly from the copyright holder. To view a copy of this licence, visit http://creativecommons.org/licenses/by/4.0/.

\section{References}

Abubakar, M. (2015). Reliability Based Design of Concrete Mixes Admixed with Cow Bone Ash, Unpublished Master of Engineering (MEng) Thesis, Department of Civil Engineering, Federal University of Technology, Minna, Niger State, Nigeria.

Alhaji, B. (2016). Statistical Modelling of Mechanical properties of Concrete made from Natural Coarse Aggregates from Bida Environ, Unpublished Doctor of Philosophy (PhD) Thesis, 
Department of Civil Engineering, Federal University of Technology, Minna, Niger State, Nigeria

Arora, K. R. (2003). Soil Mechnanics and Foundation Engineering, 4th Edition, Delhi Standard Publishers, USA, pp. 30-55.

Ayyub, M. B., Beach, J. E., \& Packard, W. T. (1995). Methodology for the development of reliability-based design criteria for surface ship structures'. Naval Engineers Journal., 107, 45-61. https://doi.org/10.1111/j.1559-3584.1995.tb02573.x.

Barambu, A. U., Uche, O. A. U., \& Abdulwahab, M. T. (2017). "Reliability-based code calibration for load and safety factors for the design of a simply supported steel beam." USEP: Journal of Research Information in Civil Engineering, Vol. 14, No 1 , pp. 1275-1291.

BS 12 (1996). Specification for Portland Cement. British standard Portland. British standard institute. 2 Park Street, London WIA 2BS.

BS 882 (1992). Specification for aggregates from natural sources for concrete. British Standard Institution. 2 Park Street, London WIA 2BS.

BS 1881 Part 116, (1983). Method for Determining Compressive Strength of Concrete Cubes, British Standard Institution, Her Majesty Stationary office London

BS EN 1008. (2002). Mixing water for concrete: Specification for sampling, testing and assessing the suitability of water, including water recovered from concrete industry as mixing water for concrete. London: British Standard Institution.

Castaldo, P., Palazzo, B., \& Mariniello, A. (2017). Effects of axial force on the time-variant structural reliability of ageing r.c cross-sections subjected to chloride-induced corrosion. Elsevier (Engineering Structures) 130, 261-274.
Costaldo, P., Gino, D., Bertagnoli, G., and Mancini, G. (2020). Resistance model uncertainty in non-linear finite element analyses of cyclically loaded reinforced concrete systems. Elsevier(Engineering Structures) 211, 1-32.

Jalayer, F., Asprone, D., Prota, A. and Manfredi, G. (2011). Multihazard upgrade Decision making for Critical infrastructure based on life-cycle cost Criteria. Earthquake Engineering and Structural Dynamics, John Wiley and Sons Ltd

Neville, A. M. and Brookes, J. J. (2008). ConcreteTechnology, Revised edition. Pearson Education Limited, Edinburgh gate, Harlow, Essex CM20 2JE, England.

Ode, T., \& Eluozo, S. N. (2016). Compressive strength Calibration of washed and unwashed locally occurring $3 / 8$ Gravel from Various water cement ratios and curing age. International Journal of Engineering and General Science., 4(1), 462-483.

Ogubiyi, M. A., Olawale, O. A., \& Ajayi, O. (2017). Effect of Granite, washed and un-washed Gravel Aggregate sizes on Engineering properties of concrete. WABER Conference, Accra, Ghana, pp 579-588.

Wen, Y. K. (2002). Reliability and performance-based design. Structural Safety (Elsevier), 23(2001), 407-428, PII: S0167-4730(02)00011-5.

Publisher's Note Springer Nature remains neutral with regard to jurisdictional claims in published maps and institutional affiliations. 